\title{
Políticas educacionais e a questão do acesso ao ensino superior: notas sobre a deseducação
}

\author{
RENATA GUEDES MOURÃO MACEDO \\ Fundação Escola de Sociologia e Política, São Paulo, São Paulo, Brasil
}

DOI 10.11606/issn.2316-9133.v28i2p26-31

No dia 26 de setembro de 2019, durante o $21^{\circ}$ Fórum Nacional de Ensino Superior Particular - evento organizado pelo Sindicato das Entidades Mantenedoras de Estabelecimentos do Ensino Superior (SEMESP), realizado em imponente prédio comercial localizado em frente ao Rio Pinheiros, na cidade de São Paulo - o Ministro da Educação do Brasil, Abraham Weintraub, sugeriu que o uso da palavra educação seria fruto da "ideologização" que teria tomado conta das salas de aulas no Brasil; reivindicava, ao contrário, o uso técnico da palavra "ensino": "quem educa é a família", afirmava Weintraub com indignação ${ }^{1}$. Na ocasião, para além das cores utilizadas na sinalização do evento - vermelho, ao invés do verde e amarelo, reivindicado pelo dirigente - discutia-se também o futuro das políticas de ensino superior brasileiras. Questionado sobre os rumos do Fundo de Financiamento Estudantil (FIES), que nos anos anteriores, de modo polêmico, disponibilizara grande quantidade de recursos para o financiamento de cursos de graduação em instituições privadas, o ministro respondeu, ríspido, para os apreensivos empreendedores do ensino presentes na sala: "O que o governo vai fazer por vocês? Nada. Vocês têm que se virar" 2 .

Para além do caráter quase psicodélico da cena - um ministro da educação que censura o uso da palavra educação, vestindo terno preto e gravata vermelha mas repreendendo publicamente os organizadores do evento por optarem pela cor associada ao "comunismo" e ao "marxismo cultural" - a performance é elucidativa do descalabro que as políticas de ensino superior passam a enfrentar desde a ascensão conservadora do governo de Jair Bolsonaro em 2019. Cortes de verbas, insultos à comunidade acadêmica e a promessa de privatização

\footnotetext{
${ }^{1}$ Informações disponíveis no site do evento https://www.semesp.org.br/fnesp/ e no jornal Folha de São Paulo, 26/09/2019, em matéria intitulada "Vocês tem que se virar", diz Weintraub a dirigentes de universidades privadas”. Disponível em https://www1.folha.uol.com.br/educacao/2019/09/voces-tem-que-se-virar-dizweintraub-a-dirigentes-de-universidades-privadas.shtml, acesso em 02/10/2019.

${ }^{2}$ Tal encenação diante dos empresários da educação apenas expressa o caráter ardiloso do ministro, já que em diversos outros momentos foram realizadas promessas de beneficiar o ensino superior particular, envolvendo, de um lado, a depreciação do ensino público e, por outro, a promessa de apoiar o setor privado, defendido como modelo ideal de ensino.
} 
parcial do ensino superior público por meio do "Future-se" são apenas algumas das iniciativas da pasta. Contudo, antes de pontuar polêmicas recentes, retomarei brevemente algumas das políticas de acesso ao ensino superior introduzidas nas últimas duas décadas no Brasil.

Começo destacando a dimensão do sistema, que praticamente quadruplicou de tamanho: entre 1995 e 2012, a matrícula no ensino superior cresceu 360\%, passando de 1,7 milhões de estudantes em 1995, para 7 milhões em 2012, incluindo matrículas em cursos presenciais e à distância. Em 2018, já eram 8,4 milhões de matrículas, sendo que apenas 25\% no setor público (INEP, 2019). Especialmente a partir de 2004, novas políticas educacionais com foco em marcadores sociais da diferença como classe e raça ganharam força, tanto para expandir o setor público como para subsidiar o ingresso de estudantes no setor privado. De modo geral, vislumbrava-se na expansão do ensino superior um importante canal de mobilidade social capaz de transformar o país. Nesse sentido, foram emblemáticas as falas do então presidente Luiz Inácio Lula da Silva, em discursos de campanha e de governo, que prometia um país em que "o filho do pedreiro iria poder virar doutor". Apostando no status que o diploma de ensino superior historicamente possuía para a população brasileira, essa foi uma das principais promessas dos mandatos petistas do período.

Considerados uns dos principais símbolos desse governo, o Programa Universidade para Todos (ProUni), implementado em 2005 por meio da lei ${ }^{\circ} 11.906 / 2005$, e o Fundo de Financiamento Estudantil (FIES), reformulado em 2010, foram emblemáticos nesse sentido (ALMEIDA, 2015; COSTA, 2019). Frequentemente analisados em conjunto, tais programas representaram importantes iniciativas para expandir o ensino superior por meio da parceria com o setor privado, com ou sem fins lucrativos. No entanto, por garantir grande volume de financiamento público para instituições privadas via isenções fiscais (no caso do ProUni) ou repasse direto (no caso do FIES), também foram alvo de diversas críticas ${ }^{3}$, especialmente por transferir recursos públicos para grandes grupos privados com fins lucrativos e dissociados da aposta de investimento em pesquisa e extensão, conforme tripé garantido na Constituição Federal de 1988. Conforme análise de André Singer sobre o período, em conjunto, tais políticas foram partes importantes do projeto mais amplo do "lulismo", que teria conciliado diminuição da pobreza com manutenção da ordem (SINGER, 2018). Assim, paralelo ao processo de ativação do mercado interno, valorização do salário mínimo, inclusão de importante contingente populacional no mercado formal de trabalho e de acesso ao consumo, deu-se a expansão do sistema de ensino superior, atraindo milhares de novos estudantes às salas de aula.

No setor público, após a implementação em 2007 do Programa de Reestruturação e Expansão das Universidades Federais (REUNI), instituído pelo governo Lula para promover a expansão da rede pública federal no país, passou-se a discutir a democratização de tais

\footnotetext{
${ }^{3}$ Conforme síntese crítica de Henrique Costa (2019, p. 308), o ProUni pode ser considerado como "uma tecnologia de gestão social desenhada pelo governo Lula que, ao mesmo tempo, dá seguimento a um modelo de reprodução da força de trabalho semiqualificada e de baixa remuneração".
} 
espaços de ensino. Assim, alguns anos depois, a presidente Dilma Rousseff sancionou a Lei de Cotas (Lei Federal n ${ }^{\circ}$ 12.711/2012) para as universidades públicas federais, dando voz às reivindicações de distintos movimentos sociais, principalmente o movimento negro, sobre as desigualdades de acesso ao ensino superior gratuito que seguia privilegiando elites brancas (Fiori et al, 2017) ${ }^{4}$. Analisando conjuntamente tais políticas educacionais, é interessante notar que, enquanto o setor público, especialmente pela implementação da Lei de Cotas, foi marcado por intenso debate sobre as categorias raça/cor, no ensino superior privado predominou o debate sobre as categorias de classe e de renda. Assim, especialmente o mercado de ensino superior com fins lucrativos mobilizou intensamente categorias de classe definidas por estratos econômicos, com especial atenção às classes "B e C" .

Apesar dos pesares, as mudanças foram significativas: conforme analisam Amélia Artes e Arlene Ricoldi, em pesquisa sobre estudantes negros no ensino superior (2015), em 2000, apenas 19\% dos estudantes de graduação no Brasil eram negros, fatia que passou para 35\% em 2010. Quando se articulam as variáveis sexo e cor/raça, foram as mulheres negras que apresentaram as maiores taxas de crescimento na graduação: 294,9\% de aumento nas matrículas, seguidas de homens negros, com 284,9\% de expansão (ARTES; RICOLDI, 2015, p. 869).

Ainda assim, vale lembrar que nesse mesmo processo ocorreu um grande crescimento do setor privado de ensino. Em 2018, 88,2\% das instituições de ensino superior (IES) eram privadas e 75,4\% dos universitários brasileiros estavam matriculados em instituições particulares (INEP, 2019), a grande maioria em cursos noturnos ou à distância (EAD). Se o processo de privatização e mercantilização do ensino superior brasileiro ocorria desde o final dos anos 1960, nas últimas duas décadas atinge patamares sem precedentes, tornando-se "um caso único no mundo" no que se refere à neoliberalização do ensino superior (LAVAL, 2019, p. 13). Conforme análise de Helena Sampaio et al. (2019), ocorreu um processo histórico em que simultaneamente se deu a ampliação do acesso com a manutenção de todas as suas hierarquias.

Se a ambivalência era, em minha interpretação, a marca central de tais políticas de ensino superior introduzidas nas primeiras décadas dos anos 2000, com a virada política conservadora registrada no Brasil em 2019 ocorreram inflexões importantes (Macedo, 2019). Sob o governo de Jair Bolsonaro, os discursos oficiais sobre o ensino superior

\footnotetext{
${ }^{4}$ Nas universidades públicas paulistas, contudo, tais políticas foram implementadas posteriormente, após muitas movimentações políticas, com destaque para o sistema de cotas sociais e raciais da Universidade de São Paulo (USP) implementado em 2017.

5 Entre as categorias utilizadas para mensurar a estratificação social, existem as chamadas "classes socioeconômicas", que podem ser definidas a partir de critérios como renda domiciliar, renda per capita e potencial de consumo. Em diversas dessas classificações, se convencionou nomear os estratos por letras, iniciando o topo da pirâmide social na letra A - os mais ricos -, finalizando na letra E, os mais pobres. No Brasil, entre os institutos que utilizam tais classificações, destaca-se o Critério Brasil, da Associação Brasileira de Empresas de Pesquisa (ABEP), amplamente utilizado pelo mercado. Conferir Almeida e Macedo (2015).
} 
brasileiro passaram a enfatizar novos rumos: "a ideia de universidade para todos não existe", universidade é lugar de "balbúrdia" e "o Estado brasileiro não tem condições de atender a demanda do ensino superior" ${ }^{8}$, foram algumas das falas públicas dos Ministros da Educação noticiadas no primeiro semestre de 2019. Em meio a tais polêmicas, houve um contingenciamento inédito das verbas do ensino superior federal em maio de $2019^{9}$, mais de 5 mil bolsas de pósgraduação da CAPES foram cortadas ou bloqueadas no mês setembro ${ }^{10}$, o ProUni, ao invés de ofertar apenas bolsas de ensino presencial, passou a oferecer cada vez mais bolsas de Ensino à Distância $(E A D)^{11}$. O governo lançou, ainda, uma consulta pública para um projeto ironicamente intitulado "Future-se", o qual pressiona as universidades públicas federais a se tornarem "empreendedoras de si mesmas", captando seus próprios recursos por meio de fundações e organizações sociais (OS) ${ }^{12}$.

Tudo aponta para a manutenção, ou mesmo crescimento, das desigualdades internas ao sistema de ensino superior, em que poucos estudantes poderão acessar cursos e instituições de excelência, enquanto a grande maioria dos matriculados têm de se contentar com um ensino de segunda linha, processo conhecido como "estratificação horizontal do ensino superior" (RIBEIRO; SCHLEGEL, 2015). A imagem dos "excluídos do interior", mobilizada por Bourdieu e Champagne (1998) ao analisar o processo ambíguo de expansão

\footnotetext{
${ }^{6}$ Discurso do primeiro ministro da educação de Jair Bolsonaro, o teólogo Ricardo Vélez Rodríguez, em fevereiro de 2019. Jornal Valor Econômico, reportagem de Hugo Passarelli, 28/01/2019. Disponível em: https://www.valor.com.br/brasil/6088217/ideia-de-universidade-para-todos-nao-existe-diz-ministro-daeducacao, acesso em 14/02/2019.

${ }^{7}$ Discurso do segundo ministro da educação de Jair Bolsonaro, o Abraham Weintraub, em abril de 2019. Jornal Estadão, 30/04/2019. Disponível em: https://educacao.estadao.com.br/noticias/geral,mec-cortara-verba-deuniversidade-por-balburdia-e-ja-mira-unb-uff-e-ufba,70002809579, acesso em 18/07/2019.

${ }^{8}$ Discurso de Abraham Weintraub no $12^{\circ}$ Congresso Brasileiro de Ensino Particular, realizado em 6/06/2019. Disponível em https://www1.folha.uol.com.br/educacao/2019/06/ministro-da-educacao-defendefortalecimento-de-ensino-superior-particular.shtml, acesso em 18/07/2019.

${ }^{9} \mathrm{O}$ contingenciamento de 30\% para todas as universidades federais foi anunciado em 30/04/2019. Disponível em https://www1.folha.uol.com.br/educacao/2019/04/mec-estende-corte-de-30-de-verbas-a-todasuniversidades-federais.shtml, acesso em 18/07/2019.

10 Conferir reportagem "Capes terá corte de 5.613 bolsas a partir de setembro". Disponível em: https://educacao.uol.com.br/noticias/2019/09/02/capes-tera-corte-de-5613-bolsas-a-partir-desetembro.htm, acesso em 01/11/2019.

11 Informações disponíveis na reportagem "Prouni tem menor oferta de bolsas integrais e para cursos presenciais”, Folha de São Paulo, 04/07/2019. Disponível em: https://www1.folha.uol.com.br/educ acao/2019/07/prouni-tem-menor-oferta-de-bolsas-integrais-e-para-cursos-presenciais.shtml, 18/07/2019.

12 Segundo informações disponíveis no site do MEC em 01/11/2019 "O Future-se, programa do governo Bolsonaro para universidades e institutos federais, vai valorizar o professor com base no empreendedorismo e na inovação." Diz ainda: "O programa foi lançado para promover maior autonomia financeira nas universidades e institutos federais por meio de incentivo à captação de recursos próprios e ao empreendedorismo". Disponível em: http://portal.mec.gov.br/component/tags/tag/52641, acesso em $01 / 11 / 2019$.
} 
do sistema educacional francês, torna-se mais atual do que nunca para analisar o cenário educacional brasileiro.

Para além do esforço de resistirmos ao desmonte de políticas educacionais constituídas no período anterior, trata-se simultaneamente do desafio de compreendermos esse processo histórico recente, cada vez mais marcado por discursos de ódio, censura e perseguição aos pesquisadores envolvidos com direitos humanos, gênero e sexualidade (PINHEIRO-MACHADO; SCALCO, 2018; MIGUEL, 2016).

Nos anos 1960, ao debater os "dilemas no ensino superior brasileiro", Florestan Fernandes já questionava o lugar ainda instável do sistema universitário no país, marcado por visões negativas, anti-intelectualistas e restritivas. Em sua interpretação para o período, enquanto a universidade brasileira não se inserisse "no horizonte intelectual do homem comum" (Florestan ainda utilizava o masculino como linguagem universal), estas não teriam a estabilidade e a respeitabilidade que tais instituições historicamente possuíam nos "países velhos". Tornava-se necessário, portanto, "mudanças radicais de mentalidade” (1966, p. 207), tornando o sistema universitário parte efetiva do desenvolvimento nacional.

$\mathrm{Na}$ atual conjuntura, marcada pela implementação estatal da deseducação, cabe questionar o lugar das políticas educacionais voltadas à democratização do ensino superior no Brasil. Diante de tantos discursos oficiais sobre educação marcados por visões negativas e anti-intelectualistas, as preocupações de Florestan Fernandes nos anos 1960 sobre a instabilidade do sistema universitário brasileiro atualizam-se. Nos resta a dedicação cotidiana à nossa atividade e a reivindicação persistente por um sistema educacional verdadeiramente democrático e plural.

\section{Referências Bibliográficas}

ALMEIDA, Wilson. Os Herdeiros e os bolsistas do ProUni na cidade de São Paulo. Educação e Sociedade, Campinas, v. 36, n. 130, p. 85-100, mar. 2015.

ALMEIDA, Heloisa Buarque; MACEDO, Renata M. "Discursos sobre a "nova classe média" na mídia: classe, gênero e raça em intersecção”. Anais do 39 Encontro Anual da Anpocs, Caxambu, MG, 2015.

BOURDIEU, Pierre; CHAMPAGNE, Patrick. "Os excluídos do interior”. In: NOGUEIRA, Maria Alice; CATANI, Afrânio. (orgs.) Escritos de Educação. Petrópolis, Vozes, 1998.

COSTA, Henrique. "Estudantes do ProUni na crise do lulismo". Revista Plural, v.26, 2019, pp. 289-311.

FERNANDES, Florestan. Educação e sociedade no Brasil. São Paulo: Dominus e Edusp, 1966. FIORI, Ana Letícia; ASSÊNSIO, Cibele; ANDRADE, Fabiana; TEIXEIRA, Jacqueline; PATRIARCA, Letizia; DAL BO, Talita. "O tempo e o vento: notas sobre a arte de burocratizar cotas na USP”. Revista de Antropologia, V.60, N.1, 2017, pp.55-83.

INEP. “Censo da Educação Superior 2018: notas estatísticas”. Brasília: Instituto Nacional de Estudos e Pesquisas Educacionais, 2019. Disponível em: http://download.inep.gov.br/ed 
ucacao_superior/censo_superior/documentos/2019/censo_da_educacao_superior_2018 -notas_estatisticas.pdf, acesso em 23/10/2019.

LAVAL, Christian. A escola não é uma empresa: o neoliberalismo em ataque ao ensino público. São Paulo: Boitempo, 2019.

MACEDO, Renata M. Escolhas possiveis: narrativas de classe e gênero no ensino superior privado. Tese (doutorado em Antropologia Social). Universidade de São Paulo, São Paulo, 2019.

MIGUEL, Luis Felipe. “Da 'doutrinação marxista' à 'ideologia de gênero' - Escola Sem Partido e as leis da mordaça no parlamento brasileiro". Revista Direito e Práxis, v.7, n.15, 2016, pp. 590-621.

PINHEIRO-MACHADO, Rosana; SCALCO, Lucia. "Da esperança ao ódio: juventude, política e pobreza do lulismo ao bolsonarismo". Cadernos IHU Ideias, 2018.

RIBEIRO, Carlos Antonio Costa e SCHLEGEL, Rogerio. "Estratificação horizontal e ensino superior no Brasil (1960 a 2010)”. In: ARRETCHE, Marta (org). Trajetórias de desigualdades: como o Brasil mudou nos últimos cinquenta anos. São Paulo, Ed. Unesp, 2015.

SAMPAIO, Helena et al. "Expanding Access to Higher Education and its (Limited) Consequences for Social Inclusion: The Brazilian Experience”. Social Inclusion, 2019, V.7, I.1, pp.7-17.

SINGER, André. O lulismo em crise: um quebra-cabeça do periodo Dilma (2011-2016). São Paulo: Companhia das Letras, 2018.

autora
Renata Guedes Mourão Macedo

É pesquisadora do Núcleo de Estudos dos Marcadores Sociais da Diferença (NUMAS-USP) e professora convidada da Fundação Escola de Sociologia e Política (FESP) de São Paulo, além de mestra e doutora em Antropologia pela Universidade de São Paulo, com graduação em Ciências Sociais pela mesma instituição. 